\title{
The effectiveness of prestorage leukocyte-reduced red blood cell transfusion on perioperative inflammatory response with a miniaturized biocompatible bypass system
}

\author{
Kagami Miyaji, MD, PhD, Takashi Miyamoto, MD, PhD, Satoshi Kohira, CCCP, Kei-ichi Itatani, MD, \\ Takahiro Tomoyasu, MD, Hajime Sato, MD, PhD, and Kuniyoshi Ohara, MD, PhD
}

\begin{abstract}
Objective: Since 2007, the Japanese Red Cross Blood Center has provided prestorage leukocyte-reduced red blood cell concentrates in which the leukocytes were reduced soon after collection. We have established a miniaturized bypass system $(140 \mathrm{~mL})$ to reduce the perioperative inflammatory responses. This study was designed to reveal the effectiveness of leukocyte-reduced red blood cell concentrate transfusion on perioperative inflammatory responses in pediatric cardiac surgery.
\end{abstract}

\begin{abstract}
Methods: Between May 2006 and June 2008, 50 consecutive patients weighing less than $5 \mathrm{~kg}$ who underwent a surgical procedure with red blood cell concentrate transfusion using a miniaturized bypass system were reviewed retrospectively. Twenty-five patients before 2007 received stored red blood cell concentrate in which leukocytes were reduced with a filter just before transfusion (group A). After 2007, 25 patients received the prestorage leukocyte-reduced red blood cell concentrate transfusion (group B). The postoperative peak C-reactive protein level, peak white blood cell count, peak neutrophil count, percentage body weight gain, inotrope score, plasma lactate concentration, postoperative mechanical ventilation time, and length of intensive care unit stay were compared as the perioperative inflammatory response and morbidity for both groups.
\end{abstract}

Results: There were no significant differences in peak white blood cell count, peak neutrophil count, percentage body weight gain, and inotrope score between the groups. The peak C-reactive protein level in group A was significantly greater than that in group $\mathrm{B}(6.7 \pm 4.7 \mathrm{vs} 4.2 \pm 3.6 \mathrm{mg} / \mathrm{dL}, P<.05)$. The lactate concentration at 12 and 24 hours after surgical intervention in group A was significantly greater than that in group B $(3.1 \pm 2.5$ vs $1.9 \pm$ $1.1 \mathrm{mmol} / \mathrm{L}[P<.05]$ and $2.2 \pm 0.2 \mathrm{vs} 1.4 \pm 0.2 \mathrm{mmol} / \mathrm{L}[P<.05]$, respectively $)$ The postoperative mechanical ventilation time and intensive care unit stay in group A were significantly greater than those in group B $(5.9 \pm 7.4$ vs $2.1 \pm 2.0$ days $[P<.05]$ and $9.8 \pm 7.9$ vs $5.0 \pm 2.1$ days $[P<0.05]$, respectively). Multivariate analyses showed that the leukocyte-reduced red blood cell concentrate transfusion reduced the peak C-reactive protein level (in milligrams per deciliter; coefficient, $-2.95 ; 95 \%$ confidence interval $[\mathrm{CI}],-4.66$ to $-0.93 ; P=.003$ ), postoperative mechanical ventilation time (in days; coefficient, $-3.41 ; 95 \% \mathrm{CI},-6.07$ to $-0.74 ; P=.013$ ), and intensive care unit stay (in days; coefficient, $-4.51 ; 95 \% \mathrm{CI},-7.37$ to $-1.64 ; P=.003$ ).

Conclusions: Our study revealed that in neonates and small infants, compared with transfusions with stored red blood cell concentrate, transfusion of leukocyte-reduced red blood cell concentrates was associated with reduced perioperative inflammatory responses and improved clinical outcomes. (J Thorac Cardiovasc Surg 2010;139:1561-7)

It is well known that cardiopulmonary bypass (CPB) activates perioperative systemic inflammatory responses because the contact of blood components with CPB circuits is one of the major causes of inflammation. ${ }^{1,2}$ In neonates and infants the surface area of the CPB circuit is proportion-

\footnotetext{
From the Department of Cardiovascular Surgery, Kitasato University School of Medicine, Sagamihara, Japan, and the Department of Public Health, University of Tokyo, School of Medicine, Tokyo, Japan.

Disclosures: None.

Received for publication May 25, 2009 ; revisions received Aug 16, 2009; accepted for publication Oct 3, 2009; available ahead of print Dec 28, 2009

Address for reprints: Kagami Miyaji, MD, Department of Cardiovascular Surgery, Kitasato University School of Medicine, 1-15-1 Kitasato, Sagamihara, Kanagawa 228-8555, Japan (E-mail: kagami111@aol.com). $0022-5223 / \$ 36.00$

Copyright (C) 2010 by The American Association for Thoracic Surgery doi:10.1016/j.jtcvs.2009.10.016
}

ately much larger than in adults relative to the patients' size and blood volume. The hyperinflammatory state is an important contributor to post-CPB organ dysfunction in neonates and small infants. ${ }^{1,2}$

Because of the small circulating volume of blood, extreme hemodilution occurs when a large $\mathrm{CPB}$ circuit is used. In that event a homologous blood transfusion is required before and during CPB in neonates and small infants. Since 2005, we have applied a miniaturized (minimum, $140 \mathrm{~mL}$ ) and biocompatible poly (2-methoxyethylacrylate) (PMEA)-coated bypass system $^{3}$ to reduce the perioperative inflammatory responses and avoid homologous blood transfusion. ${ }^{4,5}$ We can prime the bypass circuits without blood products for patients weighing more than $5 \mathrm{~kg}$. For neonates and small infants weighing less than $5 \mathrm{~kg}$, homologous blood transfusion is still needed. 


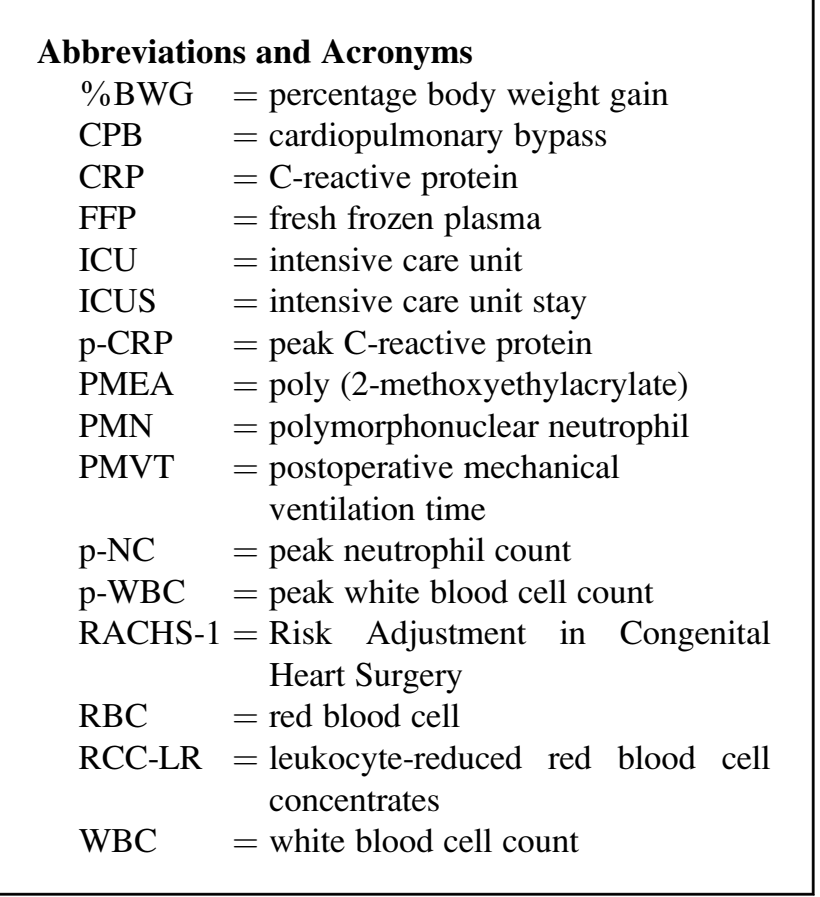

However, whole-blood transfusion generates an inflammatory response and might contribute to organ dysfunction after CPB. ${ }^{6}$ The circuit priming with fresh whole blood is associated with an increased length of stay in the intensive care unit (ICU) and increased perioperative fluid overload. ${ }^{6}$ These results suggested that neutrophils remaining in the fresh whole blood can be activated and release elastase, resulting in the perioperative inflammatory response seen after $\mathrm{CPB}$.

During storage of red blood cell (RBC) concentrates, the leukocytes release cytokines and enhance polymorphonuclear neutrophil (PMN) priming. ${ }^{7,8}$ These cytokines prime polymorphonuclear leukocytes for cytotoxicity, prompting the release of lytic enzymes during bypass. The prestorage leukocyte removal reduced the cytokine levels in stored RBCs. ${ }^{9}$ Since 2007, the Japanese Red Cross Blood Center has provided prestorage leukocyte-reduced RBC concentrates (RCC-LR) in which leukocytes were reduced before storage (Figure 1).

This study was designed to reveal the effectiveness of RCCLR transfusion for perioperative inflammatory responses in neonates and small infants weighing less than $5 \mathrm{~kg}$.

\section{MATERIALS AND METHODS}

Between May 2006 and June 2008, 50 consecutive patients weighing less than $5 \mathrm{~kg}$ who underwent a surgical procedure with an RBC transfusion using a miniaturized bypass system in the Kitasato University Hospital were reviewed retrospectively.

All the patients received an $\mathrm{RBC}$ transfusion in the priming of $\mathrm{CPB}$. The mean age and body weight were $3.2 \pm 2.9$ months (range, 2 days-12 months), and $3.9 \pm 0.9 \mathrm{~kg}$ (range, $2.3-4.9 \mathrm{~kg}$ ), respectively. There were 25 male and 25 female patients.
The Japanese Red Cross Society discontinued providing conventional stored RBCs after January 2007. Twenty-five patients before 2007 received stored RBCs in which leukocytes were reduced with a filter just before transfusion (group A). After 2007, 25 patients received the RCC-LR transfusion (group B, Figure 1). The type of procedures and Risk Adjustment in Congenital Heart Surgery 1 (RACHS-1) scores ${ }^{10}$ in both groups are shown in Table 1.

\section{Miniaturized Biocompatible Bypass System}

Our miniaturized CPB system was reported previously. ${ }^{4}$ A low-prime oxygenator and reservoir (Priming volume, $40 \mathrm{~mL}$; Baby RX; Terumo, Inc, Tokyo, Japan), arterial filters (15 mL; Filtia; JMS, Inc, Hiroshima, Japan), and a smaller and shortened extracorporeal circuit were needed to achieve a low-priming-volume CPB system. To shorten the circuit, the $\mathrm{CPB}$ roller pump was placed close enough to the operative field to minimize the tubing length. Our CPB system consisted of a distant roller-pump head, a remote-controlled unit, and a sterilized sheet. The distant roller pump and remote-controlled unit (TONOKURA Compo III; Tonokura Medical, Inc, Tokyo, Japan) allow maximal proximity to the operative field. The sterilized sheet $(50 \mathrm{~mm} \times 100 \mathrm{~mm}$; SteriSheet; Tonokura Medical, Inc), which is made of polyvinyl chloride, acts as a protective barrier between the first assistant and the CPB unit. ${ }^{4}$ The arterial, venous, and suction tubes are attached to the sheet and then covered by an unwoven polypropylene sheet. The tubes were $3 / 16$ inch in diameter at the pump heads, and the rest of the tubes were $5 / 32$ inch in diameter. By using this system, the total length of the circuit was reduced to about $280 \mathrm{~cm}$, and its priming volume was reduced to $65 \mathrm{~mL}$. The minimum priming volume of this system is currently $140 \mathrm{~mL}$, with $15 \mathrm{~mL}$ of the reservoir level. The biocompatible surface coating can reduce the inflammatory response and improve the outcome of cardiac surgery. PMEA is one of the potential coating materials, and PMEA-coated circuits have already been reported to suppress the inflammatory response in clinical settings. ${ }^{3}$ We have used the PMEA-coated bypass system successfully for all such patients since January 2005.

\section{CPB Techniques}

We monitored mixed venous oxygen saturation and regional cerebral oxygenation using near-infrared spectroscopy (INVOS 5100; Somanetics, Inc, Troy, Mich) during CPB and maintained these values at greater than $70 \%$ and $50 \%$, respectively. The plasma lactate level (in millimoles per liter) was also monitored during bypass. Blood gas management was performed with the $\mathrm{pH}$-stat strategy. High-flow $\left(200 \mathrm{~mL} \cdot \mathrm{kg}^{-1} \cdot \mathrm{min}^{-1}\right)$ normal-to-mild hypothermic $\left(32^{\circ} \mathrm{C}\right) \mathrm{CPB}$ was used. $\mathrm{CPB}$ with regional cerebral perfusion through the right innominate artery at a moderate hypothermic temperature $\left(25^{\circ} \mathrm{C}\right)$ was selected for patients undergoing aortic arch repair, such as the Norwood procedure and interruption repair. Deep hypothermic cardiac arrest was not used in any patients. Crystalloid cardioplegic solution (10 $\mathrm{mL} / \mathrm{kg}$ ) was administered every 20 minutes. After termination of the bypass, modified ultrafiltration was performed with a polymethylmethacrylate hemofilter in all patients. Modified ultrafiltration was started with an ultrafiltration rate of $20 \mathrm{~mL} \cdot \mathrm{kg}^{-1} \cdot \mathrm{min}^{-1}$ for 10 minutes. The heparinization was neutralized by protamine sulfate until the activated coagulation time had normalized. The remaining blood in the CPB circuit was returned to the patient within the operative day. Methylprednisolone sodium succinate ( 30 mg/kg; Solu-Medrol; Pharmacia \& Upjohn Co, New York, NY) was routinely given to all patients before bypass. Aprotinin was not used in this study.

\section{Study Protocol}

The patients' body weight gain was estimated by measuring the preoperative and postoperative (immediately after the operation) body weight in all patients. The body weight gain was expressed as percentage body weight gain $(\% \mathrm{BWG})$ in this study. Blood examinations, including measurement of C-reactive protein (CRP) levels, ${ }^{11}$ white blood cell counts 


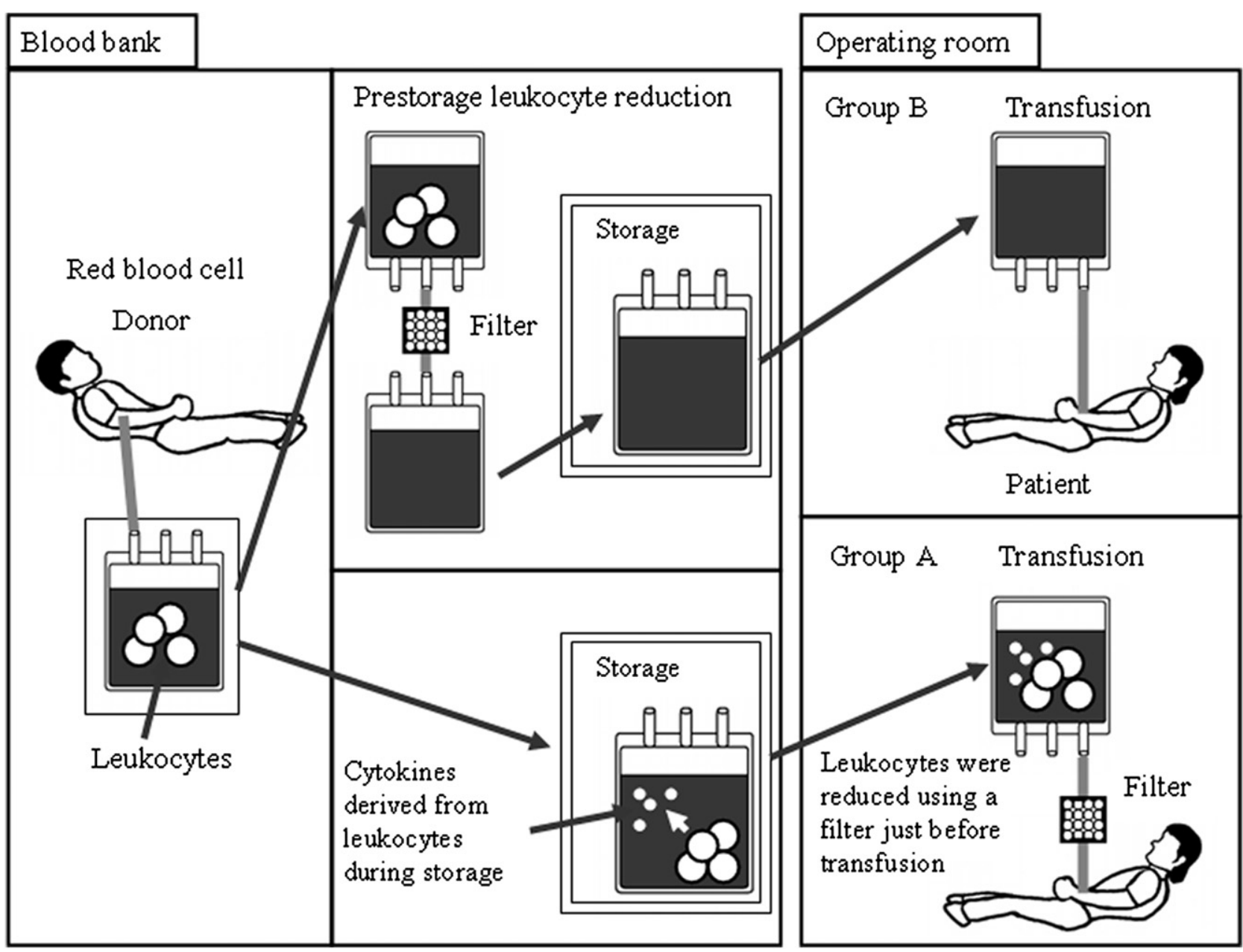

FIGURE 1. Prestorage leukocyte-reduced red blood cells.

(WBCs), and neutrophil counts (NCs), were performed at 12, 24, 48, and 72 hours postoperatively for each patient. The plasma lactate concentrate was measured at $0,12,24$, and 36 hours postoperatively for each patient. An inotropic support score was calculated at 24 hours after arrival in the ICU by means of the following formula, using drug dosages expressed as micrograms per kilogram per minute: Dopamine + Dobutamine + (Epinephrine $\times 100)+($ Milrinone $\times 10) .{ }^{6}$ The inotrope score was obtained at $0,6,12$, 18,24 , and 36 hours postoperatively for each patient.

The \%BWG and postoperative peak C-reactive protein (p-CRP) level, peak white blood cell count (p-WBC), peak neutrophil count (p-NC), plasma lactate concentrate, inotrope score, postoperative mechanical ventilation time (PMVT), and length of intensive care unit stay (ICUS) were compared as indications of the perioperative inflammatory responses and morbidity between groups. Data on sex; body weight; CPB time; procedure time; the amount of RBCs, fresh frozen plasma (FFP), and platelets transfused; and the complexity of the procedure (RACHS-1 scores) were collected from all patients.

\section{Statistical Analyses}

First, descriptive statistics of the subjects were obtained. Second, univariate analyses were performed between groups A and B. The p-CRP level, p-WBC, p-NC, \%BWG, plasma lactate concentration, inotrope score, PMVT, and ICUS with the other variables were examined. Subsequently, multivariate analysis was performed. For continuous variables (body weight, age, $\mathrm{CPB}$ time, procedure time, blood transfusion, \%BWG,
p-CRP level, p-WBC, p-NC, plasma lactate concentration, and inotrope score), Spearman's rank correlation coefficients are shown with significance. The RACHS-1 score was first treated as a continuous variable and then also as an ordinal (categorical) variable. The stepwise multiple regression analysis was used to obtain a set of independent/explanatory variables that best predicted the dependent variables (p-CRP level, p-WBC, p-NC, $\%$ BWG, PMVT, and ICUS). Explanatory variables were entered and removed in a stepwise fashion at a $P$ value of .05 to produce the most accurate predictive model. When the explanatory variables in the final model were significantly correlated with the dependent variables, regression analysis was further pursued, dropping those correlated variables one by one to check the robustness of the final model to colinearity. All dependent and independent/explanatory variables are listed in Table 2 .

\section{Institutional Review Board Approval}

The institutional review board approved the use of the miniaturized bypass system, and all the data collection was performed according to the guidelines of this board.

\section{RESULTS}

\section{Univariate Analyses}

There were no operative deaths. The clinical characteristics and surgical data in both groups are shown in Table 3. 
TABLE 1. Procedure and RACHS-1 score

\begin{tabular}{llcc}
\hline $\begin{array}{c}\text { RACHS-1 } \\
\text { score }\end{array}$ & Procedure & $\begin{array}{c}\text { No. of patients } \\
\text { in group A }\end{array}$ & $\begin{array}{c}\text { No. of patients } \\
\text { in group B }\end{array}$ \\
\hline 2 & VSD & 4 & 5 \\
& BCPS & 2 & 2 \\
3 & TOF & 2 & 1 \\
& AVSD & 2 & 2 \\
& BTS +PAP & 1 & 3 \\
& DORV & 3 & 1 \\
& ASO & 1 & 2 \\
& Aortoplasty & 2 & 0 \\
& CoA/VSD & 2 & 0 \\
4 & RV-PA conduit & 0 & 1 \\
& Rastelli & 1 & 1 \\
& TAPVC & 0 & 1 \\
6 & ASO + VSD & 0 & 3 \\
\multirow{3}{*}{ Mean } & Norwood & 4 & 1 \\
\hline$R A C H S-1$, Rod & 1 & $3.2 \pm 1.3$ \\
\hline
\end{tabular}

RACHS-1, Risk Adjustment in Congenital Heart Surgery 1; VSD, ventricular septal defect closure; $B C P S$, bidirectional cavopulmonary shunt; TOF, tetralogy of Fallot repair; AVSD, atrioventricular septal defect repair; $B T S+P A P$, Blalock-Taussig shunt and pulmonary artery plasty; $D O R V$, double-outlet right ventricle; $A S O$, arterial switch operation; $C O A$, coarctation of aorta repair; $R V-P A$, right ventricle-pulmonary artery; $T A P V C$, total anomalous pulmonary venous connection repair; $D K S$, DamusKaye-Stansel anastomosis.

There were $12(48 \%)$ patients who received FFP, platelets, or both in group A and $13(52 \%)$ in group B. There were no significant differences in age, body weight, RACHS-1 score, procedure time, perfusion time, or the amount of blood transfusion (RBCs, FFP, and platelets) between the groups.

The time course of CRP level is shown in Figure 2. The CRP levels at 24 and 48 hours after surgical intervention in group A were significantly greater than those in group B ( $P=.042$ and $P=.046$, respectively). The $\mathrm{p}$-CRP level in group A was significantly greater than that in group B $(P=.042$, Table 4$)$. There were no significant differences in $\mathrm{p}-\mathrm{WBC}, \mathrm{p}-\mathrm{NC}$, and $\% \mathrm{BWG}$ values between the groups (Table 4). The time course of the plasma lactate level is shown in Figure 3. The lactate concentrates at 12 and 24

TABLE 2. Dependent and independent variables in multivariate analyses

\begin{tabular}{ll}
\hline Dependent variables & Independent variables \\
\hline Peak CRP, & Age \\
Peak WBC, & Sex \\
Peak NC & Body weight \\
$\%$ BWG, & RACHS-1 score \\
PMVT & Perfusion time \\
ICUS & Procedure time \\
& RCC-LR transfusion \\
& Amount of blood transfusion \\
& (FFP, platelets) \\
\hline$C R P$, C-reactive protein; $W B C$, white blood cell count; $N C$, neutrophil count; $\% B W G$, \\
percentage of body weight gain; $R A C H S-1$, Risk Adjustment in Congenital Heart Sur- \\
gery; $P M V T$, postoperative mechanical ventilation time; $R C C-L R$, leukocyte-reduced \\
red blood cell concentrates; $F F P$, fresh frozen plasma.
\end{tabular}

TABLE 3. Clinical characteristics and surgical data

\begin{tabular}{lccc}
\hline & $\begin{array}{c}\text { Group A } \\
(\mathbf{n = 2 5})\end{array}$ & $\begin{array}{c}\text { Group B } \\
(\mathbf{n = 2 5})\end{array}$ & $\boldsymbol{P}$ value \\
\hline Age (mo) & $3.3 \pm 2.9$ & $3.1 \pm 2.9$ & .84 \\
Body weight (kg) & $3.8 \pm 0.9$ & $3.9 \pm 0.8$ & .55 \\
RACHS-1 score & $3.3 \pm 1.5$ & $3.2 \pm 1.3$ & .92 \\
Procedure time (min) & $289 \pm 70$ & $279 \pm 79$ & .64 \\
Perfusion time (min) & $147 \pm 52$ & $134 \pm 59$ & .41 \\
RBC transfusion (mL) & $128 \pm 38$ & $129 \pm 49$ & .94 \\
FFP transfusion (mL) & $20 \pm 35$ & $34 \pm 44$ & .2 \\
Platelet transfusion (mL) & $24 \pm 39$ & $29 \pm 43$ & .65 \\
\hline RACHS-I, Ris Adus
\end{tabular}

RACHS-1, Risk Adjustment in Congenital Heart Surgery; RBC, red blood cell; FFP, fresh frozen plasma.

hours after surgical intervention in group A were significantly greater than those in group B $(P=.040$ and $P=.021$, respectively).

There were no significant differences in inotrope scores between the groups. The PMVT and ICUS in group A were significantly greater than those in group B $(P=.014$ and $P=.005$, respectively; Table 4 ).

\section{Multiple Regression Analyses}

The multiple regression analysis results are shown in Table 5. The patients' body weight, RCC-LR transfusion, and procedure time affected p-CRP levels. A 1-unit change in body weight (in kilograms) and procedure time (in minutes) increased the p-CRP level by 2.13 and $0.022 \mathrm{mg} / \mathrm{dL}$, respectively, and the use of RCC-LR reduced the p-CRP level by $2.95 \mathrm{mg} / \mathrm{dL}$. The amount of RBC transfusion, including both conventional stored RBCs and RCC-LR, affected the $\mathrm{p}-\mathrm{NC}$ and $\mathrm{p}-\mathrm{WBC}$. A 1-unit change in $\mathrm{RBC}$ transfusion volume (in milliliters) increased the $\mathrm{p}-\mathrm{WBC}$ $\left(\times 1000 / \mathrm{mm}^{3}\right)$ and $\mathrm{p}-\mathrm{NC}\left(\times 1000 / \mathrm{mm}^{3}\right)$ by the amount indicated by their corresponding coefficient values. The combination of procedure time, RCC-LR transfusion, and patients' age affected PMVT the most. Finally, the combination of RCC-LR transfusion and procedure time was the only significant variable associated with ICUS.

Time course of CRP

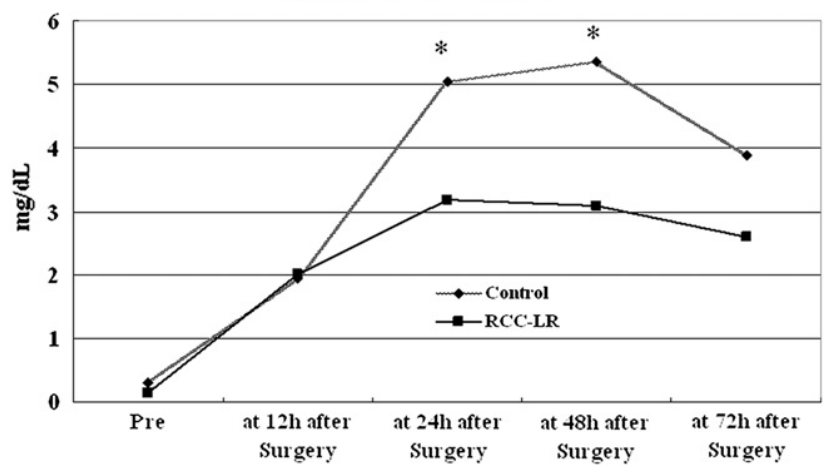

FIGURE 2. Time course of C-reactive protein $(C R P)$. RCC-LR, Leukocyte-reduced red blood cells. $* P<.05$. 
TABLE 4. Univariate analyses

\begin{tabular}{lrcc}
\hline & $\begin{array}{c}\text { Group A } \\
(\mathbf{n}=\mathbf{2 5})\end{array}$ & $\begin{array}{c}\text { Group B } \\
(\mathbf{n}=\mathbf{2 5})\end{array}$ & $\boldsymbol{P}$ value \\
\hline p-CRP $(\mathrm{mg} / \mathrm{dL})$ & $6.7 \pm 4.7$ & $4.2 \pm 3.6$ & .042 \\
p-WBC $\left(\times 1000 / \mathrm{mm}^{3}\right)$ & $17.1 \pm 5.9$ & $18.2 \pm 7.4$ & .55 \\
p-NC $\left(\times 1000 / \mathrm{mm}^{3}\right)$ & $13.5 \pm 5.1$ & $13.6 \pm 7.2$ & .93 \\
\%BWG & $3.1 \pm 2.6$ & $2.1 \pm 2.0$ & .15 \\
Lactate at 12 h ICU $(\mathrm{mmol} / \mathrm{L})$ & $3.1 \pm 2.5$ & $1.9 \pm 1.1$ & .04 \\
Lactate at 24 h ICU $(\mathrm{mmol} / \mathrm{L})$ & $2.2 \pm 0.2$ & $1.4 \pm 0.2$ & .021 \\
PMVT $(\mathrm{d})$ & $5.9 \pm 7.4$ & $2.1 \pm 2.0$ & .014 \\
ICUS (d) & $9.8 \pm 7.9$ & $5.0 \pm 2.1$ & .005 \\
\hline
\end{tabular}

$p$-CRP, Peak C-reactive protein; $p$ - $W B C$, peak white blood cell count; $p$ - $N C$, peak neutrophil count; \%BWG, percentage body weight gain; $I C U$, intensive care unit; $P M V T$, postoperative mechanical ventilation time; ICUS, length of intensive care unit stay.

\section{DISCUSSION}

Blood products are needed in cardiac surgery for small children to avoid hemodilution. Efforts have been made to minimize the unnecessary use of homologous blood in the pediatric population. ${ }^{12,13}$ The miniaturized CPB system might allow transfusion-free cardiac surgery for small infants and children. ${ }^{13}$ In our institution we have developed a priming volume $\mathrm{CPB}$ system with a minimal volume of $140 \mathrm{~mL}$. Using this system, we can prime the CPB circuit without blood products for patients weighing more than $5 \mathrm{~kg}$. In our previous report, of 70 patients weighing between $4 \mathrm{~kg}$ and $7 \mathrm{~kg}, 45(64 \%)$ underwent cardiac surgery without blood transfusion. ${ }^{4}$ As reported in our previous study, the limiting factors of bloodless cardiac surgery are not the preoperative hematocrit value or the complexity of the procedure but the CPB time and the patient's body weight. ${ }^{4}$ For patients weighing less than $5 \mathrm{~kg}$ requiring a longer $\mathrm{CPB}$ time, blood transfusion is still needed, even with the miniaturized bypass system.

The contact of blood components with CPB circuits is one of the major causes of inflammation. ${ }^{1,2}$ The reduction of priming volume can improve postoperative hemodynamics. ${ }^{14}$ We reported that the miniaturized biocompatible circuits reduced the perioperative inflammatory response,

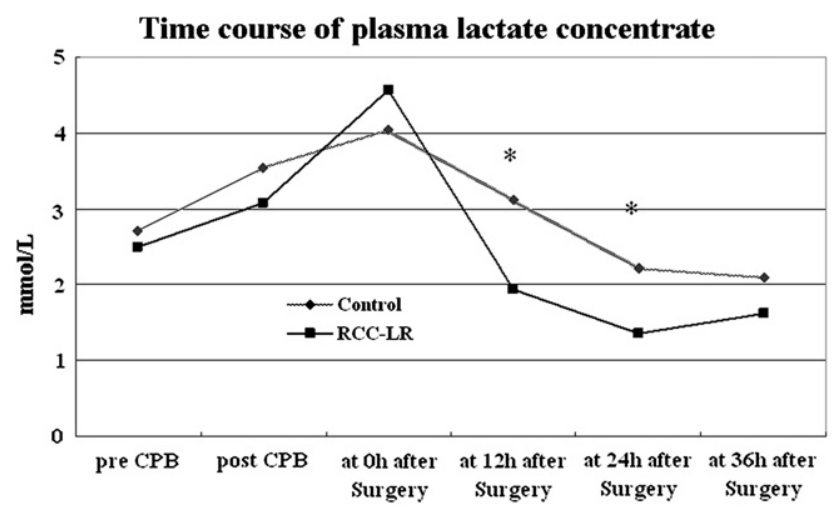

FIGURE 3. Time course of plasma lactate concentrate. $R C C$ - $L R$, Leukocyte-reduced red blood cells; $C P B$, cardiopulmonary bypass. $* P<.05$.
TABLE 5. Multiple regression analyses

\begin{tabular}{llll}
\hline & Coefficient & $\begin{array}{c}\mathbf{9 5} \% \text { Confidence } \\
\text { interval }\end{array}$ & $\begin{array}{c}\boldsymbol{P} \\
\text { value }\end{array}$ \\
\hline p-CRP (mg/dL) & & & \\
$\quad$ Body weight $(\mathrm{kg})$ & 2.13 & 1.03 to 3.22 & .001 \\
$\quad$ RCC-LR transfusion & -2.95 & -4.96 to -0.93 & .003 \\
$\quad$ Procedure time (min) & 0.022 & 0.08 to 0.36 & .005 \\
p-NC $\left(\times 1000 / \mathrm{mm}^{3}\right.$ ) & & & \\
RBC transfusion $(\mathrm{mL})$ & 0.073 & 0.038 to 0.11 & .0001 \\
p-WBC $\left(\times 1000 / \mathrm{mm}^{3}\right)$ & & & \\
RBC transfusion (mL) & 0.079 & 0.041 to 0.12 & .0001 \\
PMVT (d) & & & \\
RCC-LR transfusion & -3.41 & -6.07 to -0.74 & .013 \\
Procedure time (min) & 0.034 & 0.012 to 0.056 & .003 \\
$\quad$ Age (mo) & -0.53 & -0.99 to -0.07 & .025 \\
ICUS (d) & & & \\
$\quad$ RCC-LR transfusion & -4.51 & -7.37 to -1.64 & .003 \\
$\quad$ Procedure time (min) & 0.035 & 0.09 to 0.061 & .01 \\
\hline
\end{tabular}

$p$-CRP, Peak C-reactive protein; $R C C-L R$, leukocyte-reduced red blood cell concentrate; $p-N C$, peak neutrophil count; $R B C$, red blood cell; $p-W B C$, peak white blood cell count; $P M V T$, postoperative mechanical ventilation time; ICUS, length of intensive care unit stay.

resulting in reduced postoperative systemic edema and PMVT in neonates and small infants. ${ }^{5}$

Blood products, especially when stored, amplify the inflammatory response by delaying PMN apoptosis and enhancing PMN priming. ${ }^{7,8,14}$ It is well known that the prestorage leukocyte removal reduced the plasma cytokine levels. ${ }^{9,15}$ Leukocyte reduction soon after blood collection is better than bedside filtration to improve the quality of the blood products. Many blood centers have begun to implement prestorage leukocyte reduction in Europe. ${ }^{16}$ Since 2007, the Japanese Red Cross Blood Center has been providing prestorage RCC-LR in which the leukocytes were reduced before storage, with the current filters reducing the number of leukocytes present in blood by $4 \operatorname{logs}\left(10^{-4}\right)$, a value below which it is believed that alloimmunization or suppression does not occur. ${ }^{17}$ Before 2007, we used the stored RBC reduced leukocytes, using radiation and a filter just before transfusion. The current study revealed the effectiveness of prestorage RCC-LR transfusion for perioperative inflammatory response. Both univariate and multivariate analyses showed that use of RCC-LR decreased postoperative p-CRP levels, postoperative ventilation times, and ICUSs. There were no significant differences in inotrope scores between these groups; however, the plasma lactate concentrates at 12 and 24 hours after surgical intervention in group A were significantly greater than those in group B. RCC-LR transfusion improved the postoperative hemodynamics associated with reduced ventilation time and ICUS.

In these patient groups FFP and platelets were also transfused along with RBCs. In Japan, for FFP and platelets, prestorage leukocyte reduction has been performed since 2004 . The amount of these products transfused did not affect the postoperative inflammatory response, as shown in multivariate analyses. 
Mou and colleagues ${ }^{6}$ reported that circuit priming with fresh whole blood is associated with an increased ICUS and increased perioperative fluid overload compared with priming with RBCs. However, they did not use leukodepleted whole blood, and leukocytes in the whole blood might have caused the postoperative inflammatory responses. Therefore we have routinely used RBCs for the circuit priming. Recently, Gruenwald and associates ${ }^{18}$ reported that reconstituted fresh whole blood improves clinical outcomes compared with stored component blood therapy for neonates undergoing CPB in a randomized controlled trial. In Canada prestorage leukocyte depletion is a standard for blood component preparation. Therefore in both the reconstituted fresh whole blood group and the conventional stored component blood therapy group, leukocyte reduction was performed. In the study reported by Mou and colleagues, ${ }^{6}$ the use of blood that had not been leukodepleted could offset gains made by using fresh whole blood. Our study found an association of leukocyte depletion with some improved outcomes. The reconstituted fresh whole blood was derived from a single donor. A reduction in the number of donors might reduce the risk of transmission of infection and the inflammatory responses caused by CPB. On the other hand, the use of reconstituted fresh whole blood is not practical in many countries. Gruenwald and associates ${ }^{18}$ mentioned that an alternative strategy might include the use of reconstituted fresh components from multiple donors in which leukocyte depletion should be completed. This might replicate the effect of reconstituted fresh whole blood without the challenge of obtaining single-donor products.

In the present study there were no significant differences in $\% \mathrm{BWG}$ between groups $\mathrm{A}$ and $\mathrm{B}$, as discovered in the univariate analyses. In the multivariate analyses the use of RCC-LR and any other independent variables did not affect the \%BWG. By using our miniaturized biocompatible bypass system, postoperative inflammatory responses could be considerably suppressed. ${ }^{5}$ In fact, the data for $\%$ BWG itself, which represents perioperative fluid overload, in both groups were relatively insignificant $(3.1 \%$ in group A vs $2.1 \%$ in group B).

To achieve less invasive cardiac surgery for neonates and small infants, the following key steps should be considered. Use the miniaturized biocompatible bypass system to minimize blood transfusion, including the volume of blood products and the number of donors. Transfuse the blood components leukocyte reduced, when needed.

\section{Study Limitations}

During the past 3 years of this study period, the perfusion strategy and postoperative care were unchanged. The present study is a retrospective study, and the number of patients was small $(\mathrm{n}=50)$. Nevertheless, stepwise multiple regression analyses suggested that RCC-LR transfusion is associated with some improvements.
The Japanese Red Cross Blood Center has discontinued providing stored RBCs without leukocyte reduction since January 2007. Therefore it was impossible to perform the prospective randomized study in our country.

Because this is an observational study, it cannot rule out the possibility that some confounding factors exist that were not examined here. In the future, our results should be confirmed by means of randomized controlled trials. Furthermore, several results warrant cautious interpretation because of the small number of study subjects and the exploratory nature of the study. Adjustment of significance levels for multiple comparisons/testing could require some of our results to be accepted with reservation. We intend to reanalyze the data when larger numbers of subjects become available. The heterogeneity of patients can then be handled more meaningfully in the analyses.

\section{CONCLUSIONS}

Our study revealed that in neonates and small infants, compared with transfusions with stored RBCs, RCC-LR transfusion was associated with reduced perioperative inflammatory responses and improved clinical outcomes.

\section{References}

1. Seghaye MC, Grabitz RG, Duchateau J, et al. Inflammatory reaction and capillary leak syndrome related to cardiopulmonary bypass in neonates undergoing cardiac operations. J Thorac Cardiovasc Surg. 1996;112:687-97.

2. Ungerleider RM, Shen I. Optimizing response of the neonate and infant to cardiopulmonary bypass. Semin Thorac Cardiovasc Surg Pediatr Card Surg Annu. 2003;6:140-6

3. Ninomiya M, Miyaji K, Takamoto S. Influence of PMEA-coated bypass circuits on perioperative inflammatory response. Ann Thorac Surg. 2003;75:913-8.

4. Miyaji K, Kohira S, Miyamoto T, et al. Pediatric cardiac surgery without homologous blood transfusion, using a miniaturized bypass system in small infants with lower body weight. J Thorac Cardiovasc Surg. 2007;134:284-9.

5. Miyaji K, Miyamoto T, Kohira S, et al. Miniaturized cardiopulmonary bypass system in neonates and small infants. Interact Cardiovasc Thorac Surg. 2008;7:75-8.

6. Mou SS, Giroir BP, Molitor-Kirsch EA, et al. Fresh whole blood versus reconstituted blood for pump priming in heart surgery in infants. N Engl J Med. 2004;351: 1635-44.

7. Buttnerova I, Baumler H, Kern F, et al. Release of WBC-derived IL-1 receptor antagonist into supernatants of RBCs: influence of storage time and filtration. Transfusion. 2001;41:67-73.

8. Sparrow RL, Patton KA. Supernatant from stored red blood cell primes inflammatory cells: influence of prestorage white cell reduction. Transfusion. 2004;44: 722-30.

9. Willy C, Reithmeier W, Kuhlmann WD, et al. Leukocyte depletion of red cell components prevents exposure of transfusion recipients to neutrophil elastase. Vox Sang. 2000;78:19-27.

10. Jenkins KJ, Gauvreau K. Center-specific differences in mortality: preliminary analyses using the Risk Adjustment in Congenital Heart Surgery (RACHS-1) method. J Thorac Cardiovasc Surg. 2002;124:97-104.

11. Butler J, Rocker GM, Westaby S. Inflammatory response to cardiopulmonary bypass. Ann Thorac Surg. 1993;55:552-9.

12. van Son JA, Hovaguimian H, Rao IM, et al. Strategies for repair of congenital heart defects in infants without the use of blood. Ann Thorac Surg. 1995;59:384-8.

13. Ando M, Takahashi Y, Suzuki N. Open heart surgery for small children without homologous blood transfusion by using remote pump head system. Ann Thorac Surg. 2004;78:1717-22.

14. Karamlou T, Hickey E, Silliman CC, Shen I, Ungerleider RM. Reducing risk in infant cardiopulmonary bypass: the use of a miniaturized circuit and a crystalloid prime improves cardiopulmonary function and increases cerebral blood flow. Semin Thorac Cardiovasc Surg Pediatr Card Surg Annu. 2005;8:3-11. 
15. Muylle L, Peetermans ME. Effect of prestorage leukocyte removal on the cytokine levels in stored platelet concentrates. Vox Sang. 1994;66:14-7.

16. Wortham ST, Ortolano GA, Wenz B. A brief history of blood filtration: clot screens, microaggregate removal, and leukocyte reduction. Transfus Med Rev. 2003; 17:216-22.
17. Dzik WH. Leukoreduction of blood components. Curr Opin Hematol. 2002;9:521-6.

18. Gruenwald CE, McCrindle BW, Crawford-Lean L, et al. Reconstituted fresh whole blood improves clinical outcomes compared with stored component blood therapy for neonates undergoing cardiopulmonary bypass for cardiac surgery: a randomized controlled trial. J Thorac Cardiovasc Surg. 2008;136:1442-9.

Access to The Journal of Thoracic and Cardiovascular Surgery Online is reserved for print subscribers!

Full-text access to The Journal of Thoracic and Cardiovascular Surgery Online is available for all print subscribers. To activate your individual online subscription, please visit The Journal of Thoracic and Cardiovascular Surgery Online, point your browser to http://www.mosby.com/jtcvs, follow the prompts to activate your online access, and follow the instructions. To activate your account, you will need your subscriber account number, which you can find on your mailing label (note: the number of digits in your subscriber account number varies from 6 to 10). See the example below in which the subscriber account number has been circled:

\section{Sample mailing label}

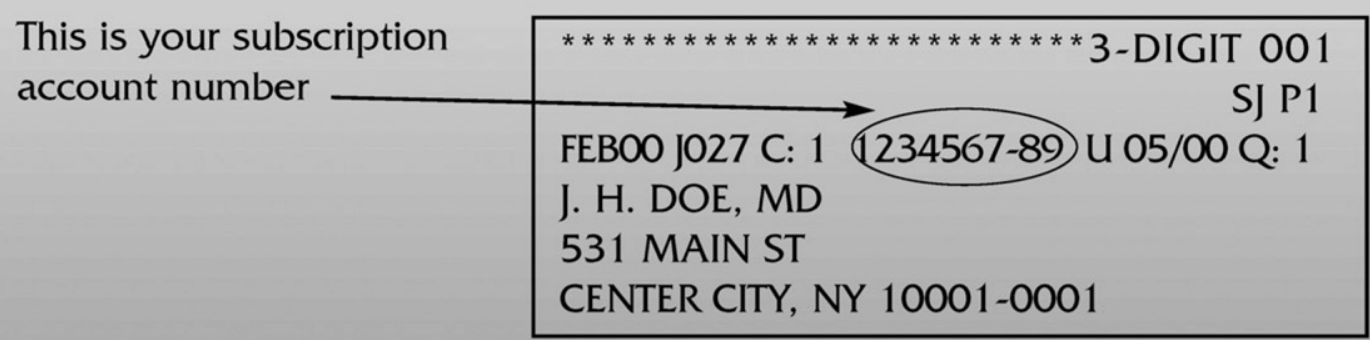

Personal subscriptions to The Journal of Thoracic and Cardiovascular Surgery Online are for individual use only and may not be transferred. Use of The Journal of Thoracic and Cardiovascular Surgery Online is subject to agreement to the terms and conditions as indicated online. 